\title{
Burnout and Mental Health Problems in Biomedical Doctoral Students
}

\author{
Gabriela A. Nagy, ${ }^{\dagger}$ Caitlin M. Fang, ${ }^{\dagger}$ Alexander J. Hish, ${ }^{\ddagger}$ Lisalynn Kelly, ${ }^{\dagger}$ \\ Christopher V. Nicchitta, Kafui Dzirasa, ${ }^{\dagger \mid \llbracket \#}$ and M. Zachary Rosenthal ${ }^{\dagger @ *}$ \\ tDepartment of Psychiatry and Behavioral Sciences, sDepartment of Cell Biology, Office of \\ Biomedical Graduate Education, "Center for Neuroengineering, and 'Duke Institute for Brain \\ Sciences, Duke University Medical Center, Durham, NC 27710; 'Duke University School of \\ Medicine, Durham, NC 27705; "Departments of Biomedical Engineering and Neurobiology and \\ @Department of Psychology and Neuroscience, Duke University, Durham, NC 27705
}

\begin{abstract}
Although burnout and mental health problems may adversely impact quality of scientific research, academic productivity, and attrition in biomedical doctoral training programs, very little research has been done on this topic. Recent studies have used brief survey methods to begin to explore burnout and mental health problems in biomedical doctoral students. In this pilot study, biomedical doctoral students $(N=69 ; 12 \%$ of enrolled biomedical doctoral students at a large research institution's school of medicine in the United States) were administered standardized psychiatric interviews and self-report questionnaires focused on dimensions of burnout, mental health symptoms, and academic outcomes. We discovered high levels of burnout, depression, and anxiety. Additionally, we identified that burnout was significantly associated with thoughts related to dropping out, subjective appraisal of employment opportunities, functional impairment due to a mental health problem, and having at least one current psychiatric disorder. These findings extend prior research indicating the presence of significant emotional health challenges doctoral students in biomedical graduate programs face involving high burnout and difficulties with the training environment. We outline several recommendations and next steps to programmatically understand and address these emerging emotional wellness concerns in biomedical doctoral students.
\end{abstract}

\section{INTRODUCTION}

Problems with burnout and mental health in biomedical doctoral students recently have been identified as significant challenges that may adversely impact quality of scientific research, academic productivity, and attrition in graduate training programs (e.g., University of California-Berkeley [UC-Berkeley] Graduate Assembly, 2014; Levecque et al., 2017). Recent years have witnessed the proliferation of calls to action to address this pressing area of concern (e.g., The Economist, 2010; Nature, 2017, 2018). Although graduate training may be intrinsically stressful, biomedical doctoral students encounter a number of unique stressors and challenges that may be associated with high burnout, problems with academic productivity, and diminished well-being (e.g., Hyun et al., 2006). Mental health problems in doctoral students may impact the quality and quantity of research output, may impose financial costs on institutions and research teams, and may adversely impact the pipeline to the research workforce (i.e., individuals prematurely quit their graduate programs; Levecque et al., 2017). Despite recent acknowledgment of such challenges, methodologically rigorous studies examining relationships among key constructs of interest, such as burnout, mental health problems, academic productivity, and training environment (e.g., quality of mentor relationship) are still lacking. Knowledge regarding these relationships would help guide the development and implementation of longitudinal studies and
Diane K. O'Dowd, Monitoring Editor Submitted Sep 27, 2018; Revised Jan 25, 2019 Accepted Mar 7, 2019

CBE Life Sci Educ June 1, 2019 18:ar27 DOI:10.1187/cbe.18-09-0198

*Address correspondence to: M. Zachary Rosenthal (mark.rosenthal@aduke.edu).

() 2019 G. A. Nagy et al. CBE-Life Sciences Education () 2019 The American Society for Cell Biology. This article is distributed by The American Society for Cell Biology under license from the author(s). It is available to the public under an Attribution-Noncommercial-Share Alike 3.0 Unported Creative Commons License (http:// creativecommons.org/licenses/by-nc-sa/3.0). "ASCB®" and "The American Society for Cell Biology ${ }^{\circledR}$ " are registered trademarks of The American Society for Cell Biology. 
programmatic approaches aimed at enhancing doctoral student well-being and productivity.

\section{Burnout and Mental Health Problems Facing Biomedical Doctoral Students}

Identifying and understanding the prevalence of burnout and mental health problems in graduate education represent a growing area of interest, especially within the biomedical science community. Recent findings from survey data indicate a majority of graduate students self-report significant levels of stress, burnout, and mental health problems (namely depression and anxiety) as compared with their counterparts (e.g., Levecque et al., 2017; Viđak et al., 2017). In the United States, two primary institutional reports have highlighted the severity of these problems among graduate students. In 2014, the University of California-Berkeley $(N=790)$ reported that 43 to $46 \%$ of graduate students in the biological sciences, physical sciences, engineering, and other related professions self-reported being depressed (UC-Berkeley Graduate Assembly, 2014). ${ }^{1}$ In 2015, the University of Arizona $(N=157)$ reported, in general, that doctoral students had a decrease in subjective ratings of mental health from the start of graduate studies and that the majority of doctoral students had "more than average" or "tremendous" stress (Smith and Brooks, 2015). ${ }^{2}$ Similar trends have also been identified internationally (e.g., McManus et al., 2002; Levecque et al., 2017; Viđak et al., 2017). Reports of high stress, burnout, and mental health problems are especially concerning, given that, despite the prevalence of these problems in graduate students, only a subset is likely to receive mental health services (e.g., Hyun et al., 2006).

\section{Burnout and Mental Health Challenges Are Associated with Poor Academic Outcomes}

Once mental health problems begin, the impact can be significant and long term. Mental health problems in student samples are associated with significant decreases in grade point average (Hysenbegasi et al., 2005), academic productivity (Eisenberg et al., 2009), and academic retention (Wilson et al., 1997; Turner and Berry, 2000; Hunt et al., 2010). Furthermore, compared with both medical students and residents, graduate science students may have significantly more frequent thoughts about dropping out of their academic programs (Toews et al., 1997). Furthermore, in a comprehensive study (the Ph.D. Completion Project) conducted across a range of institutions in the United States and Canada by the Council of Graduate Schools (2007), results indicated that that, by year 5 of graduate school, an estimated $11.8-33 \%$ of enrolled life sciences graduate students prematurely terminate their programs.

Due to the high incidence of attrition from graduate education consistently found across disciplines, a significant literature concerns the identification of risk and protective factors. An

\footnotetext{
${ }^{1}$ Total respondents in this study comprised graduate students distributed across the campus from all schools and colleges with differing academic and professional degree goals. The sample $(N=790)$ comprised students enrolled in programs in the biological sciences (12\%), physical sciences (10\%), engineering $(17 \%)$, and other related professions ( $9 \%)$.

${ }^{2}$ Doctoral respondents in this sample were presumably enrolled in a range of academic programs across the institution; however, the report did not report the percentage of doctoral students enrolled in biomedical doctoral programs.
}

important qualitative study (Gardner, 2009) sought to explore the factors contributing to doctoral attrition ${ }^{3}$; results indicated that faculty members and doctoral students diverged on the attributions they made regarding factors leading to attrition. Faculty members noted innate, individual-level factors (e.g., students lacking in ability, drive, focus, motivation, or initiative; the belief that the student should not have gone to graduate school; and personal problems such as mental health challenges). In contrast, doctoral students cited programmatic- and departmental-level factors adversely impacting individuals (e.g., personal problems such as adverse impact on relationships; departmental issues such as poor advising, lack of financial support, faculty attrition, and departmental politics; and wrong fit). Moreover, a metasynthesis (Bair and Haworth, 2004) identified several risk factors for graduate education attrition, including: poor working relationships with advisers; lack of involvement in programmatic, departmental, institutional, and professional activities and opportunities; social isolation from other students in the programs; insufficient financial support; dissatisfaction with academic programs; and challenges with aspects of completing dissertations. ${ }^{4}$

We acknowledge that factors leading to dropping out of one's doctoral program may be complex and multiply determined and may not always represent an adverse outcome. Nonetheless, preventing attrition from graduate school is a significant challenge for academic programs and institutions. Therefore, further attention focused on preventing attrition is an important area of research, considering the nascent nature of comprehensive research pertaining to attrition in biomedical graduate programs; that attrition may point to problems in departments, universities, and/or disciplines that interfere with the efficacy of graduate programs; and that it is a problem with potential waste of economic and psychological resources (Golde, 2005). Thus, to help programs manage this challenge, rigorously conducted research is needed to evaluate the relationships among burnout, mental health problems, and attrition.

\section{Graduate Training Environments Contribute to Burnout and Mental Health Problems}

In recent years, some have claimed that graduate training environments have inherent risk factors for the development of stress, burnout, and mental health problems (e.g., Schillebeeckx et al., 2013; Philips and Heywood-Roos, 2014; Shaw and Ward, 2014). During training, biomedical doctoral students face a number of key stressors that may adversely impact mental health, including long work hours (Ferreira, 2003); insufficient work-life balance (Fuhrmann et al., 2011); pressures related to managing multiple tasks such as conducting research, teaching, publishing, and finding employment (Hyun et al., 2006); strained relationships with advisers (Hyun et al., 2006); and financial stress (Furr et al., 2001). Additionally, biomedical graduate programs may direct and narrowly focus training of doctoral students on traditional academic research career paths,

\footnotetext{
${ }^{3}$ This study incorporated faculty members and graduate students across various disciplines (e.g., communications, psychology, oceanography, English, mathematics, engineering), but did not recruit biomedical departments.

${ }^{4} \mathrm{~A}$ metasynthesis refers to a qualitative methodology that synthesizes findings from a combination of both qualitative and quantitative studies.
} 
despite the context of changing supply-demand rates in the workplace (Fuhrmann et al., 2011). This shift in the workforce is largely attributable to the demographics of the biomedical workforce training model, in which the number of biomedical $\mathrm{PhDs}$ granted annually far outpaces the number of academic positions available (Ghaffarzadegan et al., 2015). As a consequence, competition for academic positions is severe. In addition, the growing use of short-term academic contracts, constrained state higher education budgets, and increased competition for research resources represent further stressors (Biron et al., 2008; Petersen et al., 2012; Walsh and Lee, 2015). In light of these factors, the academic training context is undergoing, as noted, an escalation of competitiveness (Alberts et al., 2014) that, in turn, likely contributes to stress, burnout, and mental health problems (Kinman, 2001; Ghaffarzadegan et al., 2015).

\section{Prior Interventions to Support Doctoral Students}

Despite the increasing scholarly interest in graduate student well-being (Evans et al., 2018), very little scientific work has been done to study programmatic interventions addressing burnout specifically or mental health generally. Common themes among such interventions include enforcing a more structured study program (Hovdhaugen, 2011; Viđak et al., 2017; Geven et al., 2018), enhancing both the frequency and quality of communication between students and their advisers (Tompkins et al., 2016; Cornér et al., 2017; Viđak et al., 2017; Evans et al., 2018; Geven et al., 2018), and providing increased financial support (Groenvynck et al., 2013; Van Der Haert et al., 2014; Geven et al., 2018). In contrast, interventions to reduce or prevent burnout have been extensively studied among medical trainees and physicians, and the evidence supports organizational- and program-level changes (e.g., duty-hour limitations, structural reform) as being more effective than individual-level changes (e.g., mindfulness training; Williams et al., 2015; Wasson et al., 2016; Busireddy et al., 2017; Panagioti et al., 2017; Daya and Hearn, 2018; West et al., 2018).

\section{Study Aims and Hypotheses}

Prior research has begun to highlight the need for interventions within training environments that place biomedical doctoral students at risk for burnout, mental health problems, and attrition. To date, however, most studies in this area have used brief self-report survey methodologies. Although this research generally has highlighted problems, programmatic approaches to address these problems will be greatly aided by research that uses reliable and structured diagnostic measures to characterize the scope of mental health problems, burnout, challenges to academic productivity, risk factors for attrition in biomedical doctoral students, and the relationship of these constructs to one another. Accordingly, the aims of this pilot study were 1) to begin to characterize the nature and scope of problems with burnout and mental health problems and 2) to evaluate associations among burnout and sociodemographic, academic, and mental health variables in a sample of biomedical doctoral students.

\section{METHODS}

\section{Approval from the Institutional Review Board}

We were granted approval from our institution's institutional review board (IRB; protocol 2017-0232) to conduct this study.

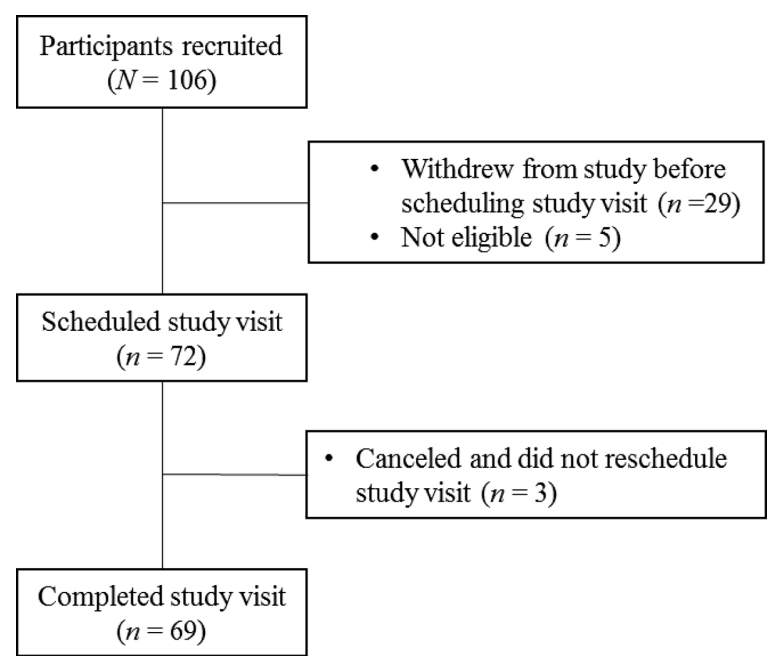

FIGURE 1. Study participant flow.

\section{Participants and Recruitment}

Study participants $(N=69)$ were biomedical doctoral students at a large research institution in the southeastern United States. The only inclusion criterion was that participants be biomedical doctoral students of any academic year housed within our institution's school of medicine (SoM). The only exclusion criterion was that participants could not be primarily students housed within biomedical programs and departments within our institution's arts and sciences division (compared with the SoM). Participants were recruited via brochures and flyers posted around campus, website postings, emails sent to graduate student Listservs, and in-person presentations at group meetings. Potential participants were instructed to contact the study coordinator directly to schedule a study visit. Upon participant-initiated contact, the study coordinator scheduled a study visit, which was conducted by a trained assessor within our laboratory. Figure 1 depicts a detailed description of study flow.

\section{Study Protocol}

Study Visit Protocol. During the study visit, participants were presented with an IRB-approved informed consent. The study visit consisted of an in-person diagnostic interview and a battery of self-report questionnaires that were completed through use of an online survey tool (Qualtrics) using a computer in our laboratory. Participants were compensated for their time (\$100). On average, completion of the protocol lasted $\sim 4$ hours. During instances when participants were unable to complete the components of the study visit in one session, they were scheduled for a second session.

Structured Clinical Interview Reliability Protocol. The structured clinical interviews (i.e., diagnostic interviews) were conducted by reliably trained assessors, including four doctoral students in clinical psychology, one postdoctoral trainee in clinical psychology, and one licensed clinical social worker. Assessors were trained in the context of several prior research studies in our laboratory that used similar research methods. The general training protocol to become proficient in conducting these structured clinical interviews comprised several stages. First, 
assessors met to discuss the assessment in general, the flow of the assessment based on study criteria, and the different modules. Second, assessors observed (i.e., either live or via a recording) a structured clinical interview conducted by a reliably trained assessor, concurrently rated responses, and afterward compared their ratings and discussed discrepancies. When discrepancies arose, each assessor explained his or her rationale guiding decision making, and discussion ensued to reach consensus. This process was repeated until there was complete agreement on diagnoses assigned (usually three times). Third, assessors were observed conducting the structured clinical interview by the reliably trained assessor. The reliably trained assessor concurrently rated responses and discussed discrepancies in ratings afterward. This process was similarly repeated until there was complete agreement in diagnoses assigned (usually three times). Contingent on aligned agreement in coding and confidence level of assessor in training, the assessor was deemed to be sufficiently reliably conducting this semistructured interview.

\section{Data Integrity Procedures}

We undertook several processes to ensure integrity of our data for structured clinical interview and self-report data. First, we randomly selected $15 \%$ of participants for whom we checked correct entry of clinical interview data (i.e., hard copies of data). Second, we downloaded de-identified self-report data from Qualtrics into statistics software (SPSS). We created syntax to compute total scale and subscale scores on our measures, per instructions from developers of each measure, when applicable. We subsequently ran frequencies on all variables of interest to identify and correct errors in data collection to determine that all data values fell within the possible response parameters.

\section{Measures}

Table 1 outlines the measures included in our study. Specifically, we outline the constructs included in each instrument, number of items, scale range, published psychometric properties, present study internal consistency (Cronbach's $\alpha$ ), and description of modifications made to original measures included herein.

Demographic Characteristics. To characterize our sample, we used a demographic questionnaire that included questions related to sociodemographic and academic characteristics. Sociodemographic questions centered on age, sex, race, ethnicity, family of origin income (Galobardes et al., 2006), ability to cover expenses, marital status, and number of children. ${ }^{5}$ Academic demographic information included academic program, year in program, thoughts related to dropping out of the program, and overall scholarly productivity (i.e., sum of manuscript productivity, conference presentations, and fellowship submissions). For our scholarly productivity variable, we gave each product equal weight (regardless of type) to reflect the quantity, not the quality or amount of time and work required

\footnotetext{
${ }^{5}$ We used family of origin income as a proxy for social position (i.e., socioeconomic status). However, we note there are other indicators of social position that we did not include herein, which may include caregiver's education, housing conditions, type of employment (before and outside graduate school), partner's income level, and assets transferred across generations, among others.
}

for completion, of each respective scholarly product generated during respondents' time in graduate school.

Clinical Diagnoses (Structured Clinical Interview). To detect the presence of current or lifetime clinical diagnoses, not inclusive of personality disorders, we used the Structured Clinical Interview for DSM-5, Research Version (SCID-5-RV; First et al., 2015). The SCID-5-RV assesses mood disorders, psychotic disorders, substance use disorders, anxiety disorders, obsessivecompulsive and related disorders, sleep disorders, feeding and eating disorders, somatic symptom and related disorders, externalizing disorders, and trauma- and stressor-related disorders.

Personality Disorders. To determine the presence of personality disorders, we used the Structured Clinical Interview for DSM-5 Personality Disorders (SCID-5-PD; First et al., 2016). The SCID-5-PD assesses whether participants meet criteria for personality disorders, including avoidant personality disorder, dependent personality disorder, obsessive-compulsive personality disorder (OCD), paranoid personality disorder, schizotypal personality disorder, schizoid personality disorder, narcissistic personality disorder, histrionic personality disorder, borderline personality disorder, and antisocial personality disorder.

Burnout. To quantify burnout, we used the School Burnout Inventory (SBI; Salmela-Aro et al., 2009). For the current study, we modified the SBI to address the workload relevant to doctoral students. The SBI used herein is a nine-item self-report questionnaire that assesses clinically relevant indices of burnout in the context of graduate school, including exhaustion at schoolwork, cynicism toward the meaning of school, and sense of inadequacy at school. Items are rated on a six-point Likert scale ranging from 1 (completely disagree) to 6 (completely agree). Cronbach's $\alpha$ for the current study was 0.90 , corresponding to good internal consistency. Prior studies have indicated this measure has acceptable reliability and validity (Salmela-Aro et al., 2009).

Depressive Symptoms. To assess the presence and severity of depressive symptoms, we used the nine-item Patient Health Questionnaire (PHQ-9; Kroenke et al., 2001). Participants rate the frequency at which they experience symptoms of major depression on a four-point Likert scale ranging from 0 (not at all) to 3 (nearly every day). Cronbach's $\alpha$ for the current study was 0.89 , corresponding to good internal consistency. Prior studies have indicated this measure has acceptable internal reliability, construct validity, criterion validity, sensitivity, and specificity (Kroenke et al., 2001).

Functional Impairment. To evaluate level of functional impairment due to the presence of mental health problems, we modified the Work and Social Adjustment Scale (WSAS), which was originally developed by Mundt et al. (2002), in order to reflect items relevant to graduate school. The WSAS used herein is a five-item self-report questionnaire that assesses the extent to which mental health symptoms impact work, social life, leisure, and daily functioning on a nine-point Likert scale ranging from 0 (no impairment at all) to 8 (very severe impairment). Cronbach's $\alpha$ for the current study was 0.91 , corresponding to excellent internal consistency. Prior studies have indicated this measure has acceptable 


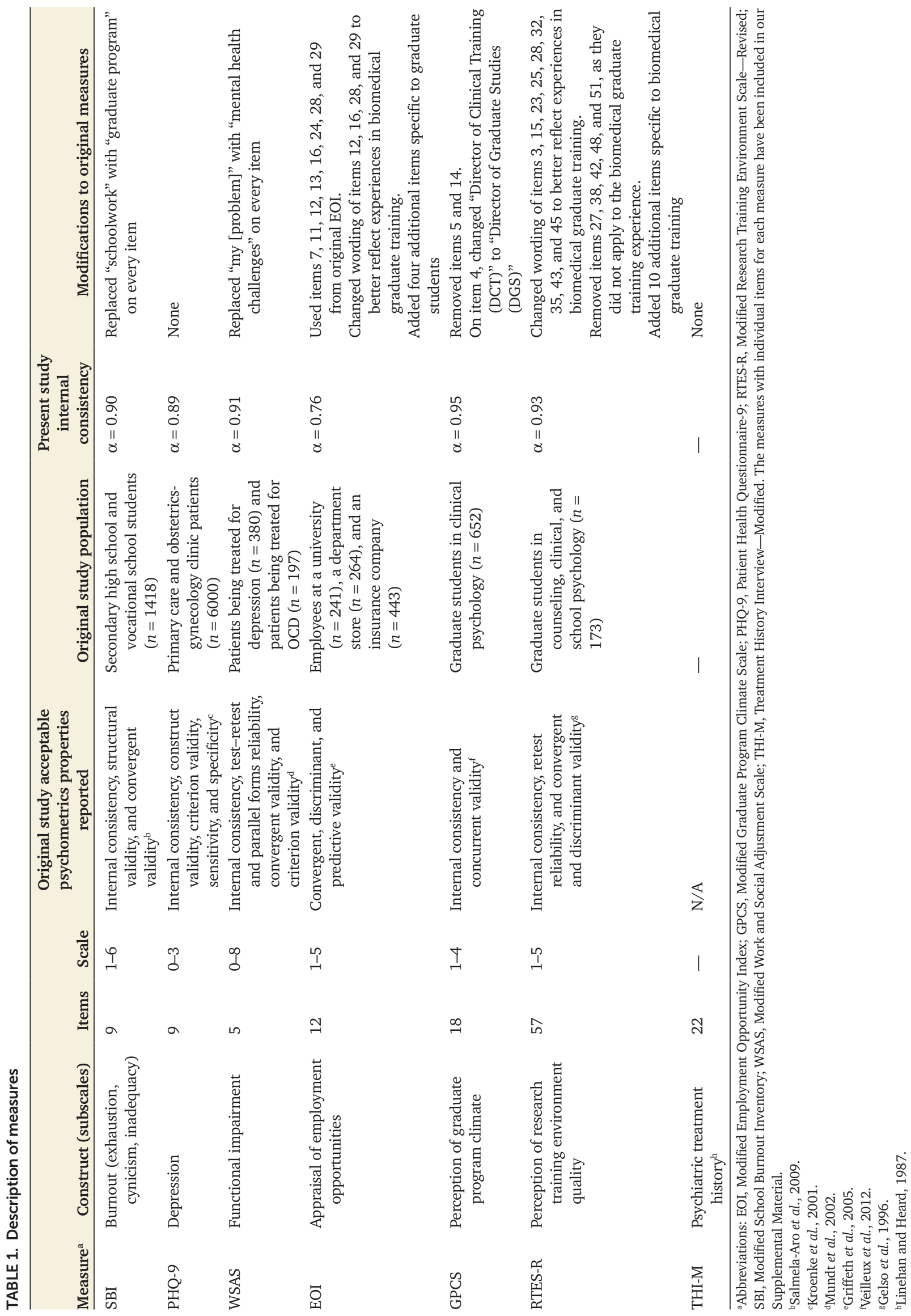


internal consistency, test-retest and parallel forms reliability, and convergent and criterion validity (Mundt et al., 2002).

Subjective Appraisal of Employment Opportunities. To assess participants' subjective appraisal of employment opportunities, we used a modified version of the Employment Opportunity Index (EOI) that was originally developed by Griffeth et al. (2005). The EOI used herein is a 12-item self-report questionnaire that assesses participants' perceptions of their likelihood of finding employment after graduating from their program, depending on their perceptions about the job market in their field and their level of preparedness for finding a career. Participants rate the extent to which they agree with statements on a five-point Likert scale ranging from 1 (strongly disagree) to 5 (strongly agree). Cronbach's $\alpha$ for the current study was 0.76 , corresponding to acceptable internal consistency. Prior studies have evidenced satisfactory convergent, discriminant, and predictive validity (Griffeth et al., 2005).

Graduate Program Climate. To measure participants' perceptions of the climate in their graduate programs, we used a modified version of the Graduate Program Climate Scale (GPCS), which was originally developed by Veilleux et al. (2012), to address issues relevant to graduate programs. The GPCS used herein is an 18-item self-report questionnaire that assesses social and emotional aspects of climate, inclusive of relationships with mentor(s) and peers. Participants respond to questions on a four-point Likert scale ranging from 1 (almost never) to 4 (almost always). Cronbach's $\alpha$ for the current study was 0.95 , corresponding to excellent internal consistency. Prior studies have indicated this measure has acceptable internal consistency and concurrent validity (Veilleux et al., 2012).

Research Training Environment Quality. To measure participants' perceived quality of their research training, we developed a measure informed by the Research Training Environment Scale-Revised (RTES-R; Gelso et al., 1996) modified for use with a biomedical graduate student sample. This measure is a 57-item self-report questionnaire wherein participants rate the extent to which they agree with statements about their graduate program on a five-point Likert scale ranging from 1 (disagree) to 5 (agree). Cronbach's $\alpha$ for the current study was 0.93, indicating excellent internal consistency.

\section{RESULTS}

\section{Demographic Characteristics}

Table 2 provides an elaborated description of demographic information. Participants were primarily in their mid-20s $(\mathrm{M}=$ 26.5; SD $=2.3$ ), white/Caucasian ( $n=48 ; 69.6 \%)$, and female $(n=42 ; 60.9 \%)$. The majority of participants were currently in a relationship, but not married ( $n=31 ; 44.9 \%)$. Our sample comprised students in all stages of their graduate training (i.e., years 1 through 6).

\section{Presence of Mental Health Problems}

Table 3 provides a detailed list of prevalence of lifetime and current psychiatric disorders. Approximately half $(n=36,52.2 \%)$ of participants currently met the threshold for at least one current psychiatric disorder diagnosis, and $66.7 \%(n=46)$ met criteria for at least one psychiatric disorder over their lifetimes.
TABLE 2. Sociodemographic characteristics of biomedical doctoral students $(N=69)^{\text {a }}$

\begin{tabular}{|c|c|c|c|}
\hline & $n(\%)$ & M (SD) & Range \\
\hline Age & & $26.5(2.3)$ & $22-33$ \\
\hline Sex: Female & $42(60.9)$ & & \\
\hline \multicolumn{4}{|l|}{ Race } \\
\hline White/Caucasian & $48(69.6)$ & & \\
\hline Asian & $16(23.2)$ & & \\
\hline Black/African American & $4(5.8)$ & & \\
\hline Other & $4(5.8)$ & & \\
\hline Middle Eastern/Arab & $2(2.9)$ & & \\
\hline Native American/American Indian & $1(1.4)$ & & \\
\hline Ethnicity: Hispanic & $12(17.4)$ & & \\
\hline Nativity: Born in the United States & $50(72.5)$ & & \\
\hline \multicolumn{4}{|l|}{ Family of origin income } \\
\hline$\$ 0-10,000$ & $4(5.8)$ & & \\
\hline$\$ 10,001-20,000$ & $3(4.3)$ & & \\
\hline$\$ 20,001-40,000$ & $7(10.1)$ & & \\
\hline$\$ 40,001-65,000$ & $9(13)$ & & \\
\hline$\$ 65,001-100,000$ & $20(29)$ & & \\
\hline$>\$ 100,000$ & $26(37.7)$ & & \\
\hline Income covers expenses: Yes & $68(98.6)$ & & \\
\hline \multicolumn{4}{|l|}{ Marital status } \\
\hline Never married, in relationship & $31(44.9)$ & & \\
\hline Never married, not in relationship & $24(34.8)$ & & \\
\hline Married & $12(17.4)$ & & \\
\hline Separated & $1(1.4)$ & & \\
\hline Divorced & $1(1.4)$ & & \\
\hline Number of children & & $0.10(0.43)$ & $0-3$ \\
\hline
\end{tabular}

The most prevalent current psychiatric diagnoses were anxiety disorders ( $n=22,31.9 \%)$, followed by mood disorders $(n=$ $10,14.5 \%)$ and personality disorders $(n=8,11.6 \%)$. The least prevalent group of disorders were substance use disorders, excluding alcohol use disorder $(n=1,1.4 \%)$, OCD and related disorders $(n=4,5.8 \%)$, feeding and eating disorders $(n=4$, $5.8 \%$ ), and attention-deficit hyperactivity disorder (ADHD; $n=$ 4, 5.8\%). No participants met diagnostic criteria for current alcohol use disorder or any psychotic disorder.

More participants had experienced at least one lifetime diagnosis of mood disorder $(n=35,50.7 \%)$ compared with anxiety disorders $(n=28,40.6 \%)$. The least prevalent lifetime diagnostic categories were OCD and related disorders $(n=6,8.7 \%)$ and feeding and eating disorders $(n=2,2.9 \%)$. No participants met the threshold for a psychotic disorder in their lifetimes.

Mental Health Prevalence in Comparison to the Total U.S. Population. Refer to Table 3 for a detailed description of prevalence for each clinical diagnostic category compared with a nationally representative sample. To contextualize our findings, we present our mental health prevalence results in comparison to the total U.S. population and for same-age counterparts 
TABLE 3. Prevalence of mental health problems compared with a nationally representative sample

\begin{tabular}{|c|c|c|c|c|c|}
\hline \multirow[b]{2}{*}{ Diagnostic category $^{\mathrm{b}}$} & \multicolumn{2}{|c|}{$\begin{array}{l}\text { Biomedical doctoral } \\
\text { students in present study } \\
(N=69)\end{array}$} & \multicolumn{3}{|c|}{ Comparator: National Comorbidity Survey Replication $(N=9282)^{\mathrm{b}}$} \\
\hline & $\begin{array}{c}\text { Past year } \\
\%(n)\end{array}$ & $\begin{array}{c}\text { Lifetime } \\
\%(n)\end{array}$ & $\begin{array}{c}\text { Past yearc } \\
\% \\
\end{array}$ & $\begin{array}{c}\text { Lifetime for total U.S. } \\
\text { population }^{\mathrm{d}} \\
\% \\
\end{array}$ & $\begin{array}{c}\text { Lifetime for individuals } \\
\text { ages } 18-29^{d} \\
\% \\
\end{array}$ \\
\hline Moode & $14.5(10)$ & $50.7(35)$ & 9.5 & 20.8 & 21.4 \\
\hline Other mood disorder ${ }^{\mathrm{f}}$ & $1.4(1)$ & $8.7(6)$ & - & - & - \\
\hline Anxiety & $31.9(22)$ & $40.6(28)$ & 18.1 & 28.8 & 30.2 \\
\hline $\mathrm{GAD}$ & $18.8(13)$ & $23.5(16)$ & 3.1 & 5.7 & 4.1 \\
\hline Social phobia & $14.5(10)$ & $15.9(11)$ & 6.8 & 12.1 & 13.6 \\
\hline Specific phobia & $2.9(2)$ & $2.9(2)$ & 8.7 & 12.5 & 13.3 \\
\hline PTSD & $2.9(2)$ & $10.1(7)$ & 3.5 & 6.8 & 6.3 \\
\hline Other trauma and stressor related & $7.2(5)$ & $8.7(6)$ & - & - & - \\
\hline OCD and related ${ }^{e, g}$ & $5.8(4)$ & $8.7(6)$ & 1.0 & 1.6 & 2.0 \\
\hline Feeding and eatinge,h & $5.8(4)$ & $2.9(2)$ & - & - & - \\
\hline $\mathrm{ADHD}$ & $5.8(4)$ & - & 4.1 & 8.1 & 7.8 \\
\hline SUD & $1.4(1)$ & $17.4(12)$ & 3.8 & 14.6 & 16.7 \\
\hline AUD & $0(0)$ & $17.4(12)$ & $\mathrm{AA}=3.1 ; \mathrm{AD}=1.3$ & $\mathrm{AA}=13.2 ; \mathrm{AD}=5.4$ & $\mathrm{AA}=14.3 ; \mathrm{AD}=6.3$ \\
\hline Other SUD ${ }^{\mathrm{i}}$ & $1.4(1)$ & $5.8(4)$ & $\mathrm{DA}=1.4 ; \mathrm{DD}=0.4$ & $\mathrm{DA}=7.9 ; \mathrm{DD}=3.0$ & $\mathrm{DA}=10.9 ; \mathrm{DD}=3.9$ \\
\hline Psychotic ${ }^{\mathrm{j}}$ & $0(0)$ & $0(0)$ & - & - & - \\
\hline Any $\mathrm{PD}^{\mathrm{e}, \mathrm{k}}$ & $11.6(8)$ & - & - & - & - \\
\hline Any disorder & & & - & - & - \\
\hline
\end{tabular}

${ }^{a}$ Regarding missing data, all study participants $(N=69)$ completed the clinical assessment, and thus none of the variables presented herein contain missing data. The percentages presented for our sample are out of a denominator of 69 .

bAbbreviations: AA, alcohol abuse; AD, alcohol dependence; ADHD, attention-deficit hyperactivity disorder; AUD, alcohol use disorder; $\mathrm{DA}$, drug abuse; DD, drug dependence; GAD, generalized anxiety disorder; MDD, major depressive disorder; OCD, obsessive-compulsive disorder; PD, personality disorder; PDD, persistent depressive disorder; PTSD, posttraumatic stress disorder; SUD, substance use disorder.

'Past-year estimates were derived from Kessler et al. (2005b).

${ }^{\mathrm{d}}$ Lifetime estimates were derived from Kessler et al. (2005a). Comparator data presented herein comprise nationally representative comprised from the National Comorbidity Survey Replication using DSM-IV diagnoses (in comparison to DSM-5, as was used in the present study).

'This category represents having any diagnosis under the corresponding diagnostic category.

fOther mood disorders comprise mood disorders other than major depression or bipolar disorder (e.g., cyclothymia, premenstrual dysphoric disorder).

${ }^{g}$ Examples of obsessive-compulsive and related disorders include OCD, trichotillomania, and hoarding disorder.

${ }^{\mathrm{h} E x a m p l e s ~ o f ~ f e e d i n g ~ a n d ~ e a t i n g ~ d i s o r d e r s ~ i n c l u d e ~ a n o r e x i a ~ n e r v o s a, ~ b u l i m i a ~ n e r v o s a, ~ a n d ~ b i n g e-e a t i n g ~ d i s o r d e r . ~}$

iOther substance use disorders comprise any substance other than alcohol (e.g., stimulant use disorder, cannabis use disorder, opioid use disorder).

${ }^{j}$ Examples of psychotic disorders include schizophrenia, schizoaffective disorder, and delusional disorder.

${ }^{k}$ Examples of personality disorders include narcissistic personality disorder, obsessive-compulsive personality disorder, and borderline personality disorder.

(i.e., ages 18-29) in a nationally representative study $(N=$ 9282; Kessler et al., 2005a,b). Our results indicate that biomedical doctoral students evidenced a higher prevalence of at least one clinical diagnosis in the past year (49.3\%) compared with the total U.S. population (26.2\%). Additionally, biomedical doctoral students also evidenced higher rates of at least one clinical diagnosis over their lifetime $(66.7 \%)$ in comparison to the total U.S. population (46.4\%) and same-age counterparts (52.4\%).

Presence of Depressive symptoms in Comparison to Other Graduate Student Samples. Refer to Table 4 for description of presence of depressive symptoms in graduate student compara- tor studies. Recent years have witnessed the publication of many studies reporting the presence of depressive symptoms in doctoral students, primarily using survey methods such as the PHQ-9 (e.g., Kroenke et al., 2001). Thus, to contextualize our findings within the broader graduate student mental health literature, we report the distribution of scores on the PHQ-9 for our sample and the compare it with other similar studies. Using interpretation ranges created by Kroenke et al. (2001), our findings suggest that $62.3 \%(n=43)$ of biomedical doctoral students in the present study fell into the minimal depression range (i.e., scores $0-4) ; 27.5 \%(n=19)$ fell into the mild depression range (i.e., scores $5-9)$; and $10.1 \%(n=7)$ fell in the moderate-to-severe depression range (i.e., scores 10-27). For 
TABLE 4. Presence of moderate-to-severe depressive symptoms compared with other student samples ${ }^{\mathrm{a}}$

\begin{tabular}{|c|c|c|c|}
\hline Sample & Study & Sample size $(N)$ & Prevalence rate \\
\hline Biomedical doctoral students ${ }^{a}$ & Present study & 69 & $10.1 \%$ \\
\hline Comparator: economics $\mathrm{PhD}$ students & Barreira et al., 2018 & 513 & $18 \%$ \\
\hline Comparator: medical students & Rotenstein et al., 2016 & 8,551 & $18.3 \%$ \\
\hline Comparator: resident physicians & Mata et al., 2015 & 3,577 & $20.9 \%$ \\
\hline Comparator: multidisciplinary master's and $\mathrm{PhD}$ students & Evans et al., 2018 & 2,279 & $39 \%$ \\
\hline
\end{tabular}

${ }^{\mathrm{a} F o r}$ studies reported, moderate-to-severe depressive symptoms corresponded to scores $\geq 10$ on the PHQ-9 (Kroenke et al., 2001).

TABLE 5. Prevalence of mental health service use in past year

\begin{tabular}{|c|c|c|c|}
\hline Sample & Study & Sample size $(N)$ & Past-year service use \\
\hline Biomedical doctoral students & Present study & & \\
\hline Total sample & & 69 & $34.4 \%$ \\
\hline Subsample: any past year mood disorder & & 6 & $33.3 \%$ \\
\hline Subsample: any past year anxiety disorder & & 21 & $47.6 \%$ \\
\hline Comparator: economics PhD students & Barreira et al., 2018 & 513 & - \\
\hline \multicolumn{4}{|l|}{ Comparator: medical students } \\
\hline All medical students & Gold et al., 2015 & 183 & $19 \%$ \\
\hline $\begin{array}{l}\text { Subsample: medical students who screened positive for depression and had } \\
\text { a history of treatment or were currently receiving treatment }\end{array}$ & Rotenstein et al., 2016 & 954 & $15.7 \%$ \\
\hline
\end{tabular}

the sake of comparison, we chose to evaluate the percentage of respondents that fell into the moderate-to-severe range $(\geq 10)$, as has been consistently reported in other studies. Biomedical doctoral students in the present study reported lower rates of moderate-to-severe depressive symptoms (10.1\%) compared with economics doctoral students (18\%; Barreira et al., 2018), medical students (18.3\%; Rotenstein et al., 2016), residents (20.9\%; Mata et al., 2015), and master's- and doctoral-level students from distinct disciplines (39\%; Evans et al., 2018). ${ }^{6}$

\section{Mental Health Service Use}

Rates of Mental Health Service Use in Biomedical Doctoral Students. Table 5 represents a detailed description of mental health service use. We found that $\sim 34.4 \%(n=22)$ of our total participant sample $(n=69)$ and $46.9 \%(n=15)$ of participants who had any current psychiatric disorder $(n=32)$ reported use of any mental health services in the past year. Importantly, there was a vast range of mental health services that participants endorsed, which included outpatient psychotherapy (e.g., individual psychotherapy, group psychotherapy), psychotropic medications, and 12-step groups (e.g., Alcoholics Anonymous, Narcotics Anonymous), among others. No participants reported having been either voluntarily or involuntarily admitted to an inpatient psychiatric facility, inpatient drug or alcohol treatment center, or detoxification center. It is important to note that there is great variation in treatment received concerning the type (e.g., psychotherapy, medication), theoretical orientation (e.g., cognitive-behavioral psychotherapy, psychodynamic psychotherapy), dose (e.g., only attending a few sessions, sustained treatment for a long period of time), and frequency of

${ }^{6}$ The sample in this last study represented diverse fields, including biological/ physical sciences, engineering, and humanities/social sciences. contact (e.g., weekly appointments, monthly appointments, appointments as needed).

Rates of Mental Health Service Use in Comparison to Other Student Samples. Refer to Table 5 for description of prevalence rates of service use in comparator studies. Overall, our findings suggest our sample sought psychiatric treatment at a higher rate than other student populations. Namely, 34.4\% of biomedical doctoral students in the present study sought mental health services in the past year, in comparison to $19 \%$ of medical students (Gold et al., 2015). Additionally, 33.3\% of biomedical doctoral students in the present study who met criteria for any mood disorder reported using mental health services in the past year-a rate that is higher in comparison to medical students who screened positive for depression ${ }^{7}$ (15.7\%; Rotenstein et al., 2016) and economics $\mathrm{PhD}$ students who reported moderate-to-severe depressive symptoms (27\%; Barreira et al., 2018). Additionally, $47.6 \%$ of biomedical doctoral students in the present study who met criteria for any anxiety disorder reported using mental health services in the past year, which is also higher in comparison to economics $\mathrm{PhD}$ students who reported moderate-to-severe anxiety symptoms (21\%; Barreira et al., 2018).

\section{Attrition}

The majority of participants reported having urges to drop out of their graduate programs in the past year. When asked how they felt about continuing their studies, $60.9 \%(n=42)$ reported

\footnotetext{
${ }^{7}$ This percentage was derived from a recent systematic review and meta-analysis of studies examining mental health problems in medical students. The percentage (15.7\%) reported herein corresponds to medical students who screened positive for depression and had a history of treatment or were currently receiving treatment.
} 
TABLE 6. Zero-order correlations among burnout, sociodemographic, academic, and mental health variables ${ }^{\mathrm{a}}$

\begin{tabular}{|c|c|c|c|c|c|c|c|c|c|c|c|c|}
\hline & 1 & 2 & 3 & 4 & 5 & 6 & 7 & 8 & 9 & 10 & 11 & 12 \\
\hline 2 & 0.14 & & & & & & & & & & & \\
\hline 3 & 0.12 & -0.04 & & & & & & & & & & \\
\hline 4 & 0.19 & -0.04 & $0.31^{* * *}$ & & & & & & & & & \\
\hline 5 & $0.37^{* * *}$ & 0.13 & 0.06 & -0.09 & & & & & & & & \\
\hline 6 & $0.51^{* *}$ & 0.12 & 0.21 & 0.16 & $0.55^{* * *}$ & & & & & & & \\
\hline 7 & $0.55^{* *}$ & $0.28^{*}$ & 0.00 & -0.03 & $0.36^{* * *}$ & $0.38 * *$ & & & & & & \\
\hline 8 & $0.60 * *$ & 0.05 & 0.20 & 0.01 & $0.47^{\text {*** }}$ & $0.56^{* * *}$ & $0.54 * *$ & & & & & \\
\hline 9 & -0.21 & -0.01 & 0.07 & 0.16 & -0.05 & -0.02 & -0.11 & $-0.24^{*}$ & & & & \\
\hline 10 & $0.62 * *$ & 0.02 & 0.18 & 0.16 & $0.32 * *$ & $0.26^{*}$ & $0.25^{*}$ & $0.41 * *$ & -0.19 & & & \\
\hline 11 & $-0.56 * *$ & -0.22 & -0.03 & -0.16 & $-0.44 * *$ & $-0.41 * *$ & $-0.30 *$ & $-0.32 * *$ & 0.070 & $-0.44 * *$ & & \\
\hline 12 & $-0.51 * *$ & -0.18 & -0.02 & -0.04 & -0.15 & -0.19 & $-0.34 * *$ & $-0.36 * *$ & $0.40 * *$ & -0.23 & $0.29 *$ & \\
\hline 13 & $-0.58 * *$ & -0.08 & -0.13 & -0.16 & $-0.30 *$ & $-0.31^{* *}$ & $-0.35 * *$ & $-0.41 * *$ & $0.38 * *$ & $-0.50 * *$ & $0.62^{* *}$ & $0.45^{* *}$ \\
\hline
\end{tabular}

aariables correspond to the following numbers: 1 = burnout; 2 = sex; 3 = race/ethnicity; 4 = family of origin salary; $5=$ lifetime clinical diagnosis; 6 = current clinical diagnosis; 7 = functional impairment; $8=$ depression severity; $9=$ scholarly productivity; $10=$ thoughts about dropping out; $11=$ graduate climate; $12=$ subjective appraisal of employment opportunities; 13 = research training environment.

*Correlation is significant at the $p<0.05$ level (two-tailed).

$* *$ Correlation is significant at the $p<0.01$ level (two-tailed).

having "fleeting thoughts about dropping out," and 8.7\% $(n=$ 6) reported "active consideration of dropping out." Approximately one-third of participants $(n=21,30.4 \%)$ reported having "no thoughts about dropping out."

\section{Associations among Academic Outcomes and Mental Health Problems}

To identify significant associations among academic outcomes and mental health problems, we used parametric correlations among continuous variables (i.e., Pearson's $r$ ) and nonparametric correlations for dichotomous variables (i.e., Spearman's rho $\left[r_{\mathrm{s}}\right]$; see Table 6). Academic variables included: overall scholarly productivity, thoughts related to dropping out, graduate program climate, subjective appraisal of employment opportunities, and research training environment quality. Mental health variables included: having at least one current psychiatric disorder, having at least one lifetime psychiatric disorder, functional impairment due to a mental health problem, and severity of current depressive symptoms. Results revealed no significant associations between subjective appraisal of employment opportunities and having either a lifetime clinical diagnosis or a current clinical diagnosis.

Nonetheless, there were several noteworthy significant associations. Having a lifetime clinical diagnosis was associated with thoughts related to dropping out $\left(r_{\mathrm{S}}=0.32, p<0.001\right)$, graduate program climate $\left(r_{\mathrm{S}}=-0.44, p<0.001\right)$, and research training environment quality $\left(r_{\mathrm{s}}=-0.30, p<0.05\right)$. Similarly, having a current clinical diagnosis was also significantly associated with thoughts related to dropping out $\left(r_{\mathrm{s}}=0.26, p<0.05\right)$, graduate program climate $\left(r_{\mathrm{s}}=-0.41, p<0.001\right)$, and research training environment quality $\left(r_{\mathrm{s}}=-0.31, p<0.001\right)$. Moreover, functional impairment was associated with thoughts related to dropping out $(r=0.25, p<0.05)$, graduate program climate $(r=-0.30, p<0.05)$, subjective appraisal of employment opportunities $(r=-0.34, p<0.001)$, and research training environment quality $(r=-0.35, p<0.001)$. In a similar manner, depression severity was also significantly associated with thoughts related to dropping out $(r=0.41, p<0.001)$, graduate program climate $(r=-0.32, p<0.001)$, subjective appraisal of employment opportunities $(r=-0.36, p<0.001)$, and research training environment quality $(r=-0.41, p<0.001)$.

\section{Burnout}

Presence of Indicators of Burnout. Refer to Table 7 for descriptive statistics for the burnout total scale and subscales, as well as other variables in the present study. There are no published norms with doctoral students using this measure for a comparative sample. Therefore, in Figure 2, we depict a series of histograms for the overall scale and subscales of the SBI to characterize levels of burnout for our sample. The skewness for the overall scale $(=0.172)$, exhaustion subscale $(=0.377)$, cynicism subscale $(=0.228)$, and inadequacy subscale $(=-0.165)$ are indicative of normal distributions (i.e., approximately symmetric), per Bulmer (1979). Visual inspection of Figure 2 confirms the conclusion that neither the overall scale nor the subscales are significantly positively or negatively skewed.

Associations among Burnout, Sociodemographic, Academic, and Mental Health Variables. We took two approaches to examine the relationships among burnout and other study variables. First, we examined zero-order correlations among all variables of interest. Second, we conducted a hierarchical linear regression to identify cross-sectional significant predictors of burnout.

Zero-Order Correlations among Burnout and Sociodemographic, Academic, and Mental Health Variables. To identify significant associations among burnout, sociodemographic (e.g., sex, family of origin income, and race/ethnicity ${ }^{8}$ ), academic, and mental health variables, we used parametric correlations among continuous variables (i.e., Pearson's $r$ ) and nonparametric correlations for dichotomous variables (i.e., Spearman's rho $\left[r_{\mathrm{s}}\right]$ ) to our outcome variable of burnout. Results revealed no significant associations among burnout and

\footnotetext{
${ }^{8}$ Our race/ethnicity variable was a dichotomous variable wherein respondents were coded as either "non-Hispanic white" or "any racial/ethnic identity other than non-Hispanic white" based on their self-report.
} 
TABLE 7. Descriptive information for continuous variables of interest ${ }^{\mathrm{a}}$

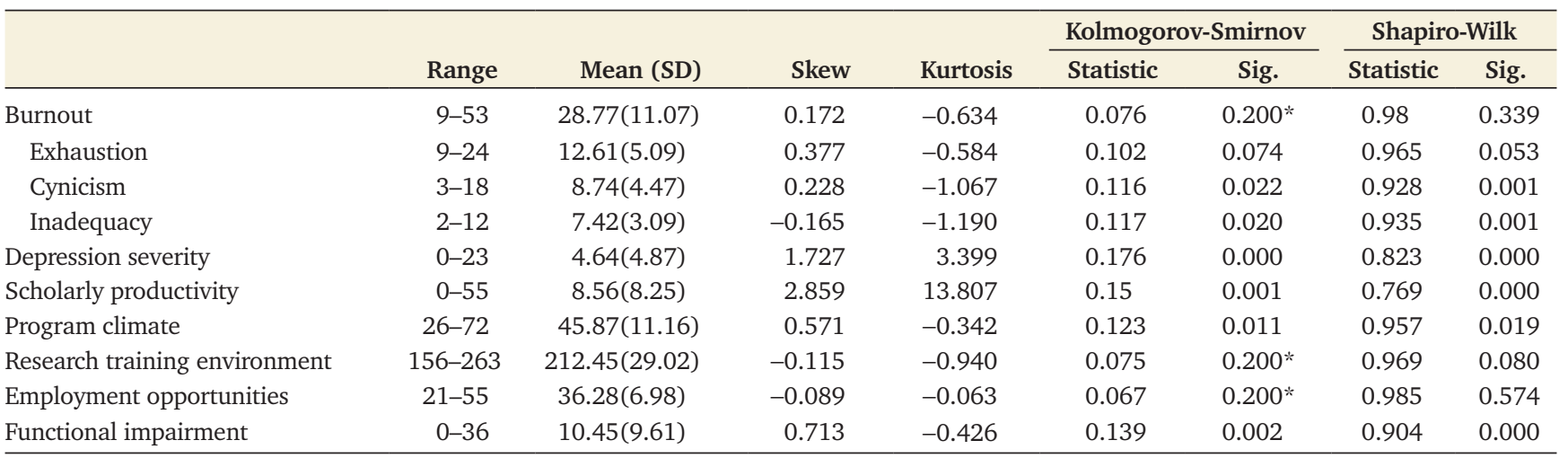

aThis table describes descriptive statistics for the total scale and subscale scores on continuous variables of interest. K-S test, Kolmogorov-Smirnov test; S-W test, Shapiro-Wilk test; Sig., significance; asterisk (*) indicates value is a lower bound of the true significance.

any of the sociodemographic variables, namely sex $\left(r_{\mathrm{S}}=0.14\right.$, $p=0.25)$, family of origin income $(r=0.19, p=0.12)$, and race/ ethnicity $\left(r_{\mathrm{s}}=0.12, p=0.32\right)$. Additionally, there was no significant association between burnout and productivity $(r=-0.21$, $p=0.09$ ).

Burnout was significantly associated with all mental health variables, including having at least one current psychiatric disorder $\left(r_{\mathrm{S}}=0.37, p<0.05\right)$, at least one lifetime psychiatric disorder $\left(r_{\mathrm{s}}=0.51, p<0.001\right)$, functional impairment $(r=0.55$, $p<0.001)$, and depressive symptoms $(r=0.60, p<0.001)$. Pertaining to academic variables, burnout was significantly associated with thoughts related to dropping out $(r=0.62, p<$ $0.001)$, graduate program climate $(r=-0.56, p<0.001)$, subjective appraisal of employment opportunities $(r=-0.51$,

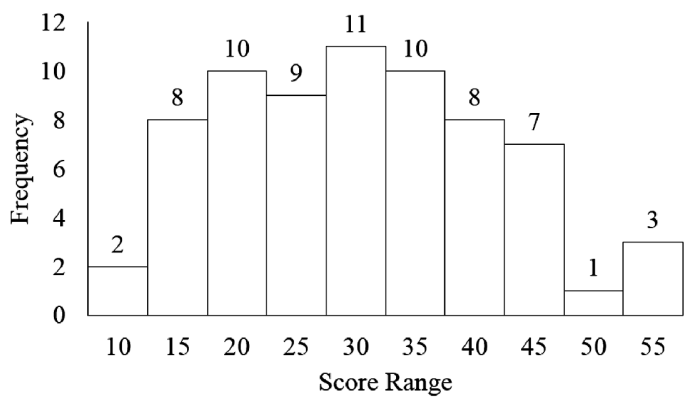

(A) Total SBI Scale

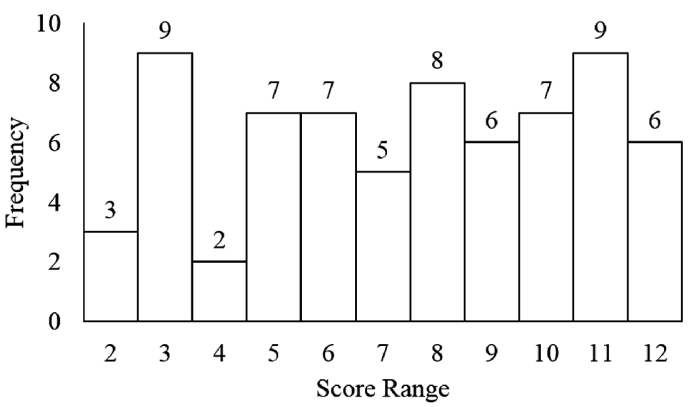

(C) SBI Inadequacy Subscale $p<0.001)$, and research training environment quality $(r=$ $-0.58, p<0.001)$.

Cross-Sectional Predictors of Burnout. To identify variables most related to burnout, we performed a hierarchical linear regression analysis with two levels (Table 8 presents full regression results). Model 1 incorporated sociodemographic variables (i.e., sex, family of origin income, and race/ethnicity), explaining $1.4 \%$ of the variance (i.e., adjusted $\left.R^{2}\right)$ in burnout, $F(3,65)=$ $1.32, p=0.28$, Akaike information criterion (AIC) $=334.65$. At this level, sociodemographic variables did not meaningfully predict burnout. In model 2 , we included both the mental health variables (e.g., having at least one current psychiatric disorder, having at least one lifetime psychiatric disorder,

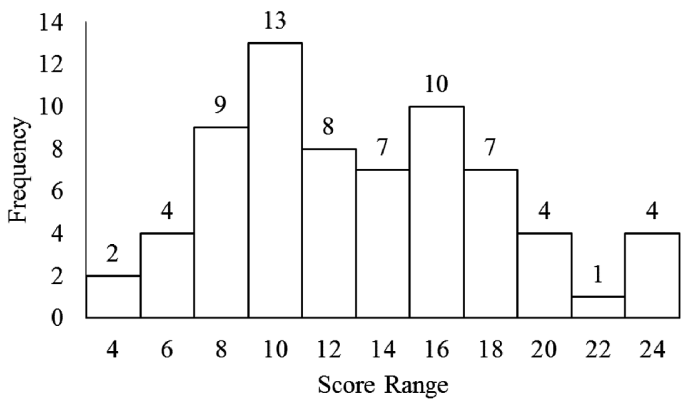

(B) SBI Exhaustion Subscale

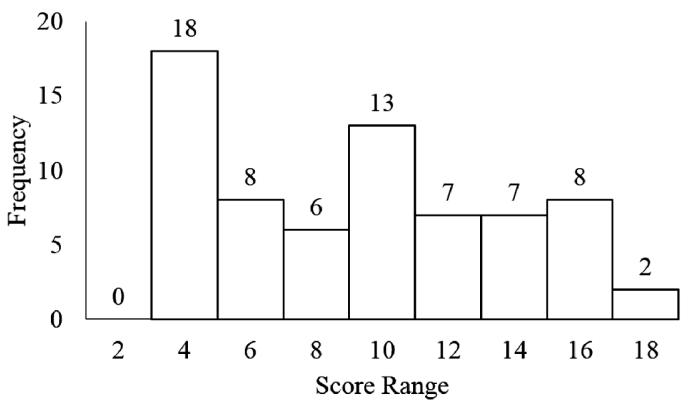

(D) SBI Cynicism Subscale

FIGURE 2. Distribution of frequency of burnout scores. 
TABLE 8. Predictors of burnout ${ }^{\mathrm{a}}$

\begin{tabular}{|c|c|c|c|c|c|c|c|c|c|c|c|}
\hline & & \multicolumn{2}{|c|}{$\begin{array}{l}\text { Unstandardized } \\
\text { coefficients }\end{array}$} & \multirow{2}{*}{$\begin{array}{c}\text { Standardized } \\
\text { coefficients }\end{array}$} & \multirow[b]{2}{*}{$t$} & \multirow[b]{2}{*}{ Sig. } & \multicolumn{3}{|c|}{ Correlations } & \multicolumn{2}{|c|}{$\begin{array}{l}\text { Collinearity } \\
\text { statistics }\end{array}$} \\
\hline \multicolumn{2}{|c|}{ Model } & B & SE & & & & Zero-order & Partial & Part & Tolerance & VIF \\
\hline \multirow[t]{4}{*}{1} & (Constant) & 11.15 & 10.66 & & 1.05 & 0.30 & & & & & \\
\hline & Sex & 3.05 & 2.72 & 0.14 & 1.12 & 0.27 & 0.14 & 0.14 & 0.14 & 1.00 & 1.00 \\
\hline & Race/ethnicity & 1.48 & 2.83 & 0.07 & 0.52 & 0.60 & 0.11 & 0.06 & 0.06 & 0.89 & 1.13 \\
\hline & Family of origin income & 1.23 & 0.96 & 0.16 & 1.28 & 0.20 & 0.19 & 0.16 & 0.15 & 0.89 & 1.12 \\
\hline \multirow[t]{13}{*}{2} & (Constant) & 34.93 & 12.00 & & 2.91 & 0.01 & & & & & \\
\hline & Sex & -0.56 & 1.75 & -0.02 & -0.32 & 0.75 & 0.14 & -0.04 & -0.02 & 0.82 & 1.22 \\
\hline & Race/ethnicity & -1.12 & 1.73 & -0.05 & -0.64 & 0.52 & 0.11 & -0.09 & -0.05 & 0.81 & 1.24 \\
\hline & Family of origin income & 0.52 & 0.62 & 0.07 & 0.84 & 0.40 & 0.19 & 0.11 & 0.06 & 0.74 & 1.36 \\
\hline & Lifetime clinical diagnosis & -1.90 & 2.24 & -0.08 & -0.84 & 0.40 & 0.37 & -0.11 & -0.06 & 0.53 & 1.88 \\
\hline & Current clinical diagnosis & 4.75 & 2.11 & 0.22 & 2.25 & 0.03 & 0.52 & 0.29 & 0.16 & 0.54 & 1.87 \\
\hline & Functional impairment & 0.25 & 0.11 & 0.22 & 2.37 & 0.02 & 0.55 & 0.30 & 0.17 & 0.57 & 1.76 \\
\hline & Depression severity & 0.29 & 0.23 & 0.13 & 1.28 & 0.21 & 0.60 & 0.17 & 0.09 & 0.49 & 2.05 \\
\hline & Productivity & 0.02 & 0.11 & 0.02 & 0.22 & 0.83 & -0.21 & 0.03 & 0.02 & 0.71 & 1.41 \\
\hline & Thoughts about dropping out & 6.57 & 1.64 & 0.35 & 4.01 & 0.00 & 0.62 & 0.47 & 0.28 & 0.64 & 1.56 \\
\hline & Graduate climate & -0.16 & 0.10 & -0.16 & -1.56 & 0.12 & -0.56 & -0.20 & -0.11 & 0.46 & 2.16 \\
\hline & Employment opportunities & -0.35 & 0.14 & -0.22 & -2.59 & 0.01 & -0.51 & -0.33 & -0.18 & 0.66 & 1.51 \\
\hline & Training quality & -0.01 & 0.04 & -0.04 & -0.34 & 0.74 & -0.58 & -0.04 & -0.02 & 0.43 & 2.31 \\
\hline
\end{tabular}

aAbbreviations: Part, semi-partial; Sig., significance; VIF, variance inflation factor.

functional impairment due to a mental health problem, and severity of current depressive symptoms) and the academic outcome variables (e.g., overall scholarly productivity, thoughts related to dropping out, graduate program climate, subjective appraisal of employment opportunities, and research training environment quality). Accounting for sociodemographic variables, the total variance (i.e., adjusted $R^{2}$ ) explained by model 2 as a whole was $66.5 \%, F(12,56)=12.26, p<0.05, R^{2}$ change $=0.667, \mathrm{AIC}=267.839$. At this level, the significant variables that meaningfully predict burnout include: thoughts related to dropping out (unstandardized $B=6.57, p<0.001$ ), subjective appraisal of employment opportunities (unstandardized $B=$ $-0.36, p=0.01$ ), functional impairment due to a mental health problem (unstandardized $B=0.25, p=0.02$ ), and having at least one current psychiatric disorder (unstandardized $B=4.75$, $p=0.03)$.

\section{DISCUSSION}

\section{Summary of Primary Findings and Implications}

This pilot study is a preliminary evaluation of burnout and mental health problems in a cross-sectional sample of biomedical doctoral students. The overall objective of the study was to begin to identify factors that significantly impact these constructs, to guide the development of longitudinal studies and programmatic interventions to support the overall wellness of biomedical doctoral students. A concerning finding from our analyses is that a high proportion of biomedical doctoral students struggle with high rates of mental health problems. Approximately half of biomedical doctoral students met the threshold for at least one clinical diagnosis in the past year, which resulted in a higher proportion compared with the total U.S. population and same-age counterparts. In addition, less than half of biomedical doctoral students having at least one clinical disorder sought out mental health services in the past year.

We found that more than two-thirds of biomedical doctoral students reported having "fleeting thoughts about dropping out" to "active consideration of dropping out" of their graduate program in the past year. We acknowledge that, while they are completing graduate education, students may be considering various career paths, some of which may not require a graduate degree or be at odds with the types of skills gained from training in biomedical graduate education. Nevertheless, we believe that thoughts related to dropping out may be an important indicator of dissatisfaction with one's graduate program, and therefore distress, thus warranting further attention.

Our study also indicates that burnout may be an important target for intervention. The overall burnout scale and the subscales (i.e., exhaustion, cynicism, and inadequacy) evidenced normal distributions. A conservative explanation of these findings may be that the majority of respondents report moderate levels of burnout, which may not be wholly unexpected, given the challenging nature of completing a doctorate. An alternative view, however, is that it may be concerning to biomedical graduate programs that a majority of students are reporting even some level of burnout, as this may pose additional barriers to well-being and academic outcomes.

Regarding predictors of burnout, hierarchical regression analysis results indicate that sociodemographic variables do not meaningfully account for burnout. When we examined the contribution of mental health and academic outcome variables to burnout, our results suggested that, combined, these variables significantly predict burnout. Within these variables, those that independently significantly contributed to burnout included: thoughts related to dropping out, subjective appraisal of employment opportunities, functional impairment due to a mental health problem, and having at least one current psychiatric disorder. These areas may be considered candidate targets for programmatic interventions designed to decrease burnout and mental health problems in biomedical doctoral students. We believe addressing these factors may have important beneficial effects on attrition, scholarly productivity, quality of science, and retention in academic careers. 
To contextualize the findings of the present study, we included comparator studies to situate our findings within the larger graduate education literature. Two important findings are that a lower percentage of biomedical graduate student respondents report moderate-to-severe depressive symptoms and a higher percentage use mental health services compared with other student populations. We highlight several important differences among these studies to understand better the implications of these results.

First, the present pilot study used a stringent structured clinical interview supplemented by self-report measures, which is in contrast to most studies, which have largely relied on survey methods (e.g., Mata et al., 2015; Evans et al., 2018). For example, the highest prevalence of depressive symptoms was reported by Evans and colleagues (2018), who recruited a large number of master's- and $\mathrm{PhD}$-level students using social media and direct email recruitment methods, thereby potentially affecting selection bias. Specifically, it may be the case that a particular subset of students, such as those experiencing high burnout and mental health problems, were differentially motivated to participate in the study, which resulted in an overrepresentation of depressive symptoms.

Second, our pilot study recruited students in one institution located in the United States, whereas some comparator studies included samples from multiple institutions (e.g., Barreira et al., 2018), countries (e.g., Mata et al., 2015; Rotenstein et al., 2016; Evans et al., 2018), and diverse training levels and programs ranging from master's degree (Evans et al., 2018) to medical residency (Mata et al., 2015). Given this variability, we posit the experiences of graduate environments of biomedical doctoral students in this pilot study may be different from those of participants in other student samples.

Third, several comparator studies comprised a composite from multiple studies. The study conducted by Rotenstein and colleagues (2016) was a systematic review and meta-analysis of 167 cross-sectional studies and 16 longitudinal studies from 43 countries. They reported the presence of moderate-to-severe depressive symptoms (i.e., PHQ-9 scores of $\geq 10$ ) in a subset of medical students in 15 studies. Mata et al. (2015) conducted a systematic review and meta-analysis of 31 cross-sectional studies and 23 longitudinal studies examining the presence of depressive symptoms in residents from different countries (i.e., 35 in North America, 9 in Asia, 5 in Europe, 4 in South America, and 1 in Africa). Moreover, their sample comprised many medical specialties (e.g., internal medicine, obstetrics/gynecology, psychiatry). The high heterogeneity of studies included in these reviews makes it a challenge to evaluate the ways in which the samples of these studies are generalizable to our biomedical doctoral student sample.

\section{Strengths of Study}

Our pilot study represents an advancement in the existing literature, in that it entailed the inclusion of validated, structured clinical interview data in addition to self-report measures. To this end, we were able to determine the extent to which problems with burnout and academic indicators were associated with mental health diagnoses. To our knowledge, this is the largest sample of biomedical doctoral students examined in a study using validated, structured clinical measures to assess the prevalence of mental health diagnoses.

\section{Study Limitations}

Our findings are presented in light of several important limitations, however. First, a key limitation is the use of a cross-sectional design, which precludes any definitive and temporally causal inferences based upon our analyses. Indeed, this study provides important information needed to conduct prospective research capable of disentangling these constructs to understand the development of burnout, mental health problems, and training-related problems over time. Second, this study was conducted as a pilot investigation, comprising a small sample size and thereby limiting power to detect significant results or carry out advanced statistical procedures (e.g., structural equation modeling). Third, as with other similar studies, biomedical doctoral students self-selected to participate in our study. Our sample $(n=69)$ represents $12 \%$ of the biomedical doctoral student population within our institution's school of medicine. Therefore, the extent to which these findings are generalizable to the larger biomedical doctoral student body within our institution and nationally is unclear. To this point, it is possible participants selected to be in the study for a variety of reasons, including high levels of dissatisfaction with their programs, alternatively high levels of satisfaction with their programs, or monetary compensation. Finally, despite our inclusion of a structured clinical interview, as with other studies, we included self-report questionnaires, which may be subject to response bias, reliance on participant insight, and individual differences in responding styles (Paulhus and Vazire, 2007).

\section{Future Directions}

Because this is an emerging area of research, there are many questions left unanswered that need to be addressed in future studies. First, we propose that future studies recruit graduate student samples beyond biomedical science disciplines to better understand the scope and breadth of burnout and mental health problems in graduate education. We hypothesize the findings presented in this pilot study may not be unique to biomedical doctoral students. A comprehensive evaluation across a range of academic disciplines may help characterize opportunities and challenges both common across graduate students and unique to biomedical doctoral students. Second, as these data indicate, the graduate training environment appears to have a strong impact on graduate student well-being. To better understand the contexts and experiences of doctoral students, future studies ought to consider collecting more granular data to characterize the laboratories, departments, programs, and institutions in which students reside. For example, qualitative methods (e.g., open-ended questions, individual and/or group interviews) would allow investigators to derive salient themes to identify unique stressors doctoral students face. Third, to increase generalizability of research findings, investigators are encouraged to employ powered studies recruiting nationally representative samples. Fourth, we encourage researchers to use longitudinal methods to evaluate the time course and persistence of indicators of burnout, mental health problems, and academic outcomes (e.g., attrition from graduate school). These methods would allow for a more nuanced understanding of the graduate climate, and determining its longitudinal effect on key constructs of interest (such as burnout and mental health) may help to identify optimal points of intervention. 
Finally, it is important to develop and test interventions aimed at improving well-being and reducing burnout across the levels of systems involved in biomedical graduate training. Thus, in addition to emphasizing solutions for individual students (e.g., referrals for psychotherapy or medications), our study suggests a more comprehensive and systems-based approach may be beneficial, including programmatic approaches targeting change among individual students, mentors, labs, programs, departments, and institutions. Possible targets for intervention may include prevention and early detection of indicators of burnout, mental health problems, and attrition (e.g., thoughts related to dropping out). Furthermore, programs are encouraged to develop systems that allow for identification of climates that may put doctoral students at risk of experiencing challenges. Thus, it may also be important to develop infrastructure to support students who report high burnout and mental health problems through systems-level interventions (e.g., psychoeducation workshops for departments, interventions to improve adviser working relationships, interventions to improve social support among students).

\section{ACKNOWLEDGMENTS}

We thank the Office of the Dean within the School of Medicine at our institution for internal funding for this research. Additionally, we thank the research personnel who aided our team with conducting the research protocol with study participants-without you this project would not have been possible; namely, we acknowledge the contributions made by Kibby McMahon, Angela Pisoni, Shelley Lampher, Daniel Seed, and Alma Vazquez-Smith.

\section{REFERENCES}

Alberts, B., Kirschner, M. W., Tilghman, S., \& Varmus, H. (2014). Rescuing US biomedical research from its systemic flaws. Proceedings of the National Academy of Sciences USA, 111(16), 5773-5777. https://doi.org/10.1073/ pnas.1404402111

Bair, C. R., \& Haworth, J. G. (2004). Doctoral student attrition and persistence: A meta-synthesis of research. In Higher education: Handbook of theory and research (pp. 481-534). Dordrecht, Netherlands: Springer.

Barreira, P., Basilico, M., \& Bolotnyy, V. (2018). Graduate student mental health: Lessons from American economics departments (Working paper). Retrieved November 29, 2018, from https://scholar.harvard.edu/files/ bolotnyy/files/bbb_mentalhealth_paper.pdf

Biron, C., Brun, J. P., \& Ivers, H. (2008). Extent and sources of occupational stress in university staff. Work, 30(4), 511-522.

Bulmer, M. G. (1979). Statistical inference. Principles of statistics (pp. 165187). New York: Dover.

Busireddy, K. R., Miller, J. A., Ellison, K., Ren, V., Qayyum, R., \& Panda, M. (2017). Efficacy of interventions to reduce resident physician burnout: A systematic review. Journal of Graduate Medical Education, 9(3), 294 301. https://doi.org/10.4300/JGME-D-16-00372.1

Cornér, S., Löfström, E., \& Pyhältö, K. (2017). The relationship between doctoral students' perceptions of supervision and burnout. International Journal of Doctoral Studies, 12, 91-106. https://doi.org/10.28945/3754

Council of Graduate Schools. (2007). PhD completion and attrition: Analysis of baseline demographic data from the PhD completion project. Retrieved January 2, 2019, from https://cgsnet.org/phd-completion -and-attrition-analysis-baseline-program-data-phd-completion-project

Daya, Z., \& Hearn, J. H. (2018). Mindfulness interventions in medical education: A systematic review of their impact on medical student stress, depression, fatigue and burnout. Medical Teacher, 40(2), 146-153.

Eisenberg, D., Golberstein, E., \& Hunt, J. B. (2009). Mental health and academic success in college. BE Journal of Economic Analysis \& Policy, 9(1) https://doi.org/10.2202/1935-1682.2191
Evans, T. M., Bira, L., Gastelum, J. B., Weiss, L. T., \& Vanderford, N. L. (2018) Evidence for a mental health crisis in graduate education. Nature Biotechnology, 36(3), 282-284. https://doi.org/10.1038/nbt.4089

Ferreira, M. (2003). Gender issues related to graduate student attrition in two science departments. International Journal of Science Education, 25(8), 969-989. https://doi.org/10.1080/09500690305026

First, M. B., Williams, J. B., Benjamin, L. S., \& Spitzer, R. L. (2016). Structured clinical interview for DSM-5 personality disorders: SCID-5-PD. Arlington, VA: American Psychiatric Association Publishing.

First, M. B., Williams, J. B. W., Karg, R. S., \& Spitzer, R. L. (2015). Structured clinical interview for DSM-5-Research version: SCID-5-RV. Arlington, VA: American Psychiatric Association.

Fuhrmann, C. N., Halme, D. G., O'Sullivan, P. S., \& Lindstaedt, B. (2011) Improving graduate education to support a branching career pipeline: Recommendations based on a survey of doctoral students in the basic biomedical sciences. CBE-Life Sciences Education, 10(3), 239-249. https://doi.org/10.1187/cbe.11-02-0013

Furr, S. R., Westefeld, J. S., McConnell, G. N., \& Jenkins, J. M. (2001). Suicide and depression among college students: A decade later. Professional Psychology: Research and Practice, 32(1), 97. https://doi.org/10.1037/ 0735-7028.32.1.97

Galobardes, B., Shaw, M., Lawlor, D. A., Lynch, J. W., \& Smith, G. D (2006). Indicators of socioeconomic position (part 1). Journal of Epidemiology \& Community Health, 60(1), 7-12. https://doi.org/10.1136/ jech.2004.023531

Gardner, S. K. (2009). Student and faculty attributions of attrition in high and low-completing doctoral programs in the United States. Higher Education, 58(1), 97-112. https://doi.org/10.1007/s10734-008-9184-7

Gelso, C. J., Mallinckrodt, B., \& Judge, A. B. (1996). Research training environment, attitudes toward research, and research self-efficacy: The revised Research Training Environment Scale. Counseling Psychologist, 24(2), 304-322. https://doi.org/10.1177/0011000096242010

Geven, K., Skopek, J., \& Triventi, M. (2018). How to increase PhD completion rates? An impact evaluation of two reforms in a selective graduate school, 1976-2012. Research in Higher Education, 59(5), 529-552. https://doi.org/10.1007/s11162-017-9481-z

Ghaffarzadegan, N., Hawley, J., Larson, R., \& Xue, Y. (2015). A note on Ph.D. population growth in biomedical sciences. Systems Research and Behavioral Science, 32(3), 402-405. https://doi.org/10.1002/sres.2324

Gold, J. A., Johnson, B., Leydon, G., Rohrbaugh, R. M., \& Wilkins, K. M. (2015) Mental health self-care in medical students: A comprehensive look at help-seeking. Academic Psychiatry, 39(1), 37-46

Golde, C. M. (2005). The role of the department and discipline in doctoral student attrition: Lessons from four departments. Journal of Higher Education, 76(6), 669-700. https://doi.org/10.1353/jhe.2005.0039

Griffeth, R. W., Steel, R. P., Allen, D. G., \& Bryan, N. (2005). The development of a multidimensional measure of job market cognitions: The Employment Opportunity Index (EOI). Journal of Applied Psychology, 90(2), 335 https://doi.org/10.1037/0021-9010.90.2.335

Groenvynck, H., Vandevelde, K., \& Van Rossem, R. (2013). The PhD track: Who succeeds, who drops out?. Research Evaluation, 22(4), 199-209. https://doi.org/10.1093/reseval/rvt010

Hovdhaugen, E. (2011). Do structured study programmes lead to lower rates of dropout and student transfer from university? Irish Educational Studies, 30(2), 237-251. https://doi.org/10.1080/03323315.2011.569143

Hunt, J., Eisenberg, D., \& Kilbourne, A. M. (2010). Consequences of receipt of a psychiatric diagnosis for completion of college. Psychiatric Services, 61(4), 399-404. https://doi.org/10.1176/ps.2010.61.4.399

Hysenbegasi, A., Hass, S. L., \& Rowland, C. R. (2005). The impact of depression on the academic productivity of university students. Journal of Mental Health Policy and Economics, 8(3), 145

Hyun, J. K., Quinn, B. C., Madon, T., \& Lustig, S. (2006). Graduate student mental health: Needs assessment and utilization of counseling services. Journal of College Student Development, 47(3), 247-266. https://doi .org/10.1353/csd.2006.0030

Kessler, R. C., Berglund, P., Demler, O., Jin, R., Merikangas, K. R., \& Walters, E. E. (2005a). Lifetime prevalence and age-of-onset distributions of DSM-IV disorders in the National Comorbidity Survey Replication. Archives of 
General Psychiatry, 62(6), 593-602. https://doi.org/10.1001/archpsyc .62.6.617, https://doi.org/10.1001/archpsyc.62.6.593

Kessler, R. C., Chiu, W. T., Demler, O., \& Walters, E. E. (2005b). Prevalence, severity, and comorbidity of 12-month DSM-IV disorders in the National Comorbidity Survey Replication. Archives of General Psychiatry, 62(6), 617627. https://doi.org/10.1001/archpsyc.62.6.617, https://doi.org/10.1001/ archpsyc.62.6.593

Kinman, G. (2001). Pressure points: A review of research on stressors and strains in UK academics. Educational Psychology, 21(4), 473-492.

Kroenke, K., Spitzer, R. L., \& Williams, J. B. (2001). The PHQ-9: Validity of a brief depression severity measure. Journal of General Internal Medicine. 16(9), 606-613. https://doi.org/10.1046/j.1525-1497.2001.016009606.x

Levecque, K., Anseel, F., De Beuckelaer, A., Van der Heyden, J., \& Gisle, L. (2017). Work organization and mental health problems in $\mathrm{PhD}$ students. Research Policy, 46(4), 868-879. https://doi.org/10.1016/j.respol.2017.02.008

Linehan, M. M., \& Heard, H. L. (1987). Treatment history interview (THI), Seattle: University of Washington.

Mata, D. A., Ramos, M. A., Bansal, N., Khan, R., Guille, C., Di Angelantonio, E., \& Sen, S. (2015). Prevalence of depression and depressive symptoms among resident physicians: A systematic review and meta-analysis. Journal of the American Medical Association, 314(22), 2373-2383. https://doi.org/10.1001/jama.2015.15845

McManus, I. C., Winder, B. C., \& Gordon, D. (2002). The causal links between stress and burnout in a longitudinal study of UK doctors. Lancet, 359(9323), 2089-2090. https://doi.org/10.1016/S0140-6736(02)08915-8

Mundt, J. C., Marks, I. M., Shear, M. K., \& Greist, J. M. (2002). The Work and Social Adjustment Scale: A simple measure of impairment in functioning. British Journal of Psychiatry, 180(5), 461-464. https://doi.org/10.1192/ bjp.180.5.461.

Nature [Editorial]. (2017, October 26). Spread your wings. Nature, 550, 429.

Nature [Editorial]. (2018, March 29). Time to talk about why so many postgrads have poor mental health. Nature, 556(5). Retrieved January 2, 2019, from www.nature.com/articles/d41586-018-04023-5

Panagioti, M., Panagopoulou, E., Bower, P., Lewith, G., Kontopantelis, E., Chew-Graham, C., ... \& Esmail, A. (2017). Controlled interventions to reduce burnout in physicians: A systematic review and meta-analysis. Journal of the American Medical Association Internal Medicine, 177(2), 195-205. https://doi.org/10.1001/jamainternmed.2016.7674

Paulhus, D. L., \& Vazire, S. (2007). The self-report method. Handbook of research methods in personality psychology (Vol. 1, pp. 224-239), New York: Guilford.

Petersen, A. M., Riccaboni, M., Stanley, H. E., \& Pammolli, F. (2012). Persistence and uncertainty in the academic career. Proceedings of the National Academy of Sciences USA, 109(14), 5213-5218. https://doi.org/10.1073/ pnas.1121429109

Phillips, S., \& Heywood-Roos, R. (2014). Job security for early career researchers is a significant factor in helping research make an impact. Impact of Social Sciences Blog.

Rotenstein, L. S., Ramos, M. A., Torre, M., Segal, J. B., Peluso, M. J., Guille, C., ... \& Mata, D. A. (2016). Prevalence of depression, depressive symptoms, and suicidal ideation among medical students: A systematic review and meta-analysis. Journal of the American Medical Association, 316(21), 2214-2236. https://doi.org/10.1001/jama.2016.17324

Salmela-Aro, K., Kiuru, N., Leskinen, E., \& Nurmi, J. E. (2009). School burnout inventory (SBI) reliability and validity. European Journal of Psychological Assessment, 25(1), 48-57. https://doi.org/10.1027/1015-5759.25.1.48

Schillebeeckx, M., Maricque, B., \& Lewis, C. (2013). The missing piece to changing the university culture. Nature Biotechnology, 31(10), 938. https://doi.org/10.1038/nbt.2706

Shaw, C., \& Ward, L. (2014, March 06). Dark thoughts: Why mental illness is on the rise in academia. The Guardian. Retrieved July 26, 2018, from www.theguardian.com/higher-education-network/2014/mar/ 06/mental-health-academics-growing-problem-pressure -university

Smith, E., \& Brooks, Z. (2015). Graduate student mental health 2015 Tucson: National Association of Graduate-Professional Students and the Graduate Professional Student Council, University of Arizona. Retrieved August 5, 2018, from http://nagps.org/wordpress/wp-content/ uploads/2015/06/NAGPS_Institute_mental_health_survey_report 2015.pdf

The Economist. (2010, December 16). The disposable academic: Why doing a PhD is often a waste of time. Retrieved July 26, 2018, from www economist.com/christmas-specials/2010/12/16/the-disposable - academic? storyid=17723223

Toews, J. A., Lockyer, J. M., Dobson, D. J., Simpson, E., Brownell, A. K., Brenneis, F., ... \& Cohen, G. S. (1997). Analysis of stress levels among medical students, residents, and graduate students at four Canadian schools of medicine. Academic Medicine, 72(11), 997-1002. https://doi.org/ 10.1097/00001888-199711000-00019

Tompkins, K. A., Brecht, K., Tucker, B., Neander, L. L., \& Swift, J. K. (2016). Who matters most? The contribution of faculty, student-peers, and outside support in predicting graduate student satisfaction. Training and Education in Professional Psychology, 10(2), 102. https://doi.org/10.1037/ tep0000115

Turner, A. L., \& Berry, T. R. (2000). Counseling center contributions to student retention and graduation: A longitudinal assessment. Journal of College Student Development, 41(6), 627-636.

University of California-Berkeley Graduate Assembly. (2014). Graduate student happiness \& well-being report. Retrieved August 1, 2018, from http://ga.berkeley.edu/wp-content/uploads/2015/04/wellbeingreport _2014.pdf

Van Der Haert, M., Arias Ortiz, E., Emplit, P., Halloin, V., \& Dehon, C. (2014). Are dropout and degree completion in doctoral study significantly dependent on type of financial support and field of research? Studies in Higher Education, 39(10), 1885-1909. https://doi.org/10.1080/03075079 .2013.806458

Veilleux, J. C., January, A. M., VanderVeen, J. W., Reddy, L. F., \& Klonoff, E. A. (2012). Perceptions of climate in clinical psychology graduate programs: Development and initial validation of the Graduate Program Climate Scale. Training and Education in Professional Psychology, 6(4), 211. https://doi.org/10.1037/a0030303

Viđak, M., Tokalić, R., Marušić, M., Puljak, L., \& Sapunar, D. (2017). Improving completion rates of students in biomedical PhD programs: An interventional study. BMC Medical Education, 17(1), 144. https://doi.org/10.1186/ s12909-017-0985-1

Walsh, J. P., \& Lee, Y. N. (2015). The bureaucratization of science. Research Policy, 44(8), 1584-1600. https://doi.org/10.1016/j.respol .2015.04.010

Wasson, L. T., Cusmano, A., Meli, L., Louh, I., Falzon, L., Hampsey, M., ... \& Davidson, K. W. (2016). Association between learning environment interventions and medical student well-being: A systematic review. Journal of the American Medical Association, 316(21), 2237-2252. https://doi .org/10.1001/jama.2016.17573

West, C. P., Dyrbye, L. N., \& Shanafelt, T. D. (2018). Physician burnout: Contributors, consequences and solutions. Journal of Internal Medicine 283(6), 516-529. https://doi.org/10.1111/joim.12752

Williams, D., Tricomi, G., Gupta, J., \& Janise, A. (2015). Efficacy of burnout interventions in the medical education pipeline. Academic Psychiatry, 39(1), 47-54. https://doi.org/10.1007/s40596-014-0197-5

Wilson, S. B., Mason, T. W., \& Ewing, M. J. (1997). Evaluating the impact of receiving university-based counseling services on student retention. Journal of Counseling Psychology, 44(3), 316. https://doi.org/10.1037/ 0022-0167.44.3.316 